\title{
Fitness to practise patterns are changing as GDC saves millions
}

\author{
By Adrian O’Dowd, BDJ News Editor
}

\section{$\mathrm{T}$} he dental regulator the General Dental Council (GDC) has managed to save almost $£ 6$ million in the past year by reducing the number of fitness to practise hearings that took place by around a third at the same time as fewer complaints were made against dentists, according to recent data.

On the surface, such a trend could be considered welcome, but dental leaders at the BDA have reacted angrily saying that it underlines their previous concerns raised over the regulator's recent decision to maintain the Annual Retention Fee (ARF) that dentists have to pay at its current level of $£ 890$ for 2019 - the highest rate of all the health regulators. third year running that complaint numbers have fallen.

\section{Regulation costs}

Overall, the GDC's total expenditure decreased to $£ 39$ million in 2017 from $£ 45.3$ million in 2016, with lower expenditure on most functions.

Dealing with FtP cases is the GDC's main driver of costs, accounting for $69 \%$ of its expenditure in 2017.

Therefore, if the regulator aims to save significant levels of money, targeting FtP is an obvious step and it is doing so.

The GDC says that throughout 2017, it had sought to drive improvements in efficiency

\section{Dealing with fitness to practise cases is the GDC's main driver of costs...}

The GDC's Annual Report and Accounts: $2017^{1}$ published in June showed that fitness to practise (FtP) and hearings costs fell by $£ 5.8$ million to $£ 20.3$ million (from $£ 26.1$ million in 2016) due to a significant reduction in the number of new cases referred for prosecution - from 333 cases in 2016 to 224 in 2017, a 32.7\% reduction.

This led to a $£ 3$ million decrease in the cost of prosecuting FtP cases by both the In-House Legal Prosecution Services (ILPS) and external legal providers.

The regulator stresses that part of the 'savings' were achieved because of a delay at the casework stage leading to delays in cases reaching the Professional Conduct Committee (PCC). Therefore, rather than being a 'saving', this was better thought of as 'deferred spend' to be seen in 2018.

At the same time, the total number of complaints received in 2017 was 1,910 which represented a $27 \%$ drop from the 2,630 complaints made in 2016. Last year was the and was still searching for and delivering business efficiencies.

The annual report says: 'Whilst we have addressed the resource pressures we encountered in 2016, fluctuations in our casework performance mean that our finances are not yet as stable as we would wish.

'As a result, we ended the year with expenditure $£ 7.1$ million lower than budgeted. We are working to better understand the detailed cost drivers of our activities and to improve our forecasting and managing of budgeted expenditure.'

The focus on FtP is clear, as the report says: 'Work is underway now to enable the development of a system of "upstream" regulation, where issues are dealt with in the right place and at the right time, with only the most serious cases being addressed by means of a Fitness to Practise investigation.

'This will not only be more proportionate, in the long term it will also allow us to deliver greater cost-efficiency' 
4 In November 2016, case examiners replaced the former Investigating Committee at the regulator and the GDC says this has resulted in a significant fall in the number of cases that proceeded to final hearings in 2017 , from $45 \%$ to $31 \%$, with resulting reductions in costs.

\section{Reforming the system}

There is an ongoing end-to-end review and improvement programme into the current FtP process, established by the regulator's Shifting the balance consultation ${ }^{2}$ of January 2017 , to see how it could become more streamlined. This 18 month review project is due for completion in June 2019.

GDC Executive Director of Fitness to Practise Transition, Tom Scott, says: 'It's an exciting time to be working at the GDC in driving forward our programme of improvement, right across the FtP process.

'We have made some really significant progress already and we are on track to complete this work by June next year. There is still a lot of hard work to be done but I'm working with a great team who are all 100\% committed to realising our goals.'

The BDA welcomes the direction of travel on FtP overall and points to a BDA survey of 2,300 dentists carried out last year that showed around three quarters (71\%) of them wanted the GDC to prioritise making fitness to practise fit for purpose.

However, the union still maintains dentists are paying a heavy price for regulation.

Alison Lockyer, Chair of the Education, Ethics and the Dental Team Working Group of the BDA, says: 'This change in emphasis is undoubtedly overdue but welcome, and we look forward to hearing more of the regulator's plans to promote local resolution.

'But, given how much FtP hearing numbers have dropped since 2014, resulting in far lower operating costs and significant savings means there can be no justification for the GDC to maintain the exorbitant ARF of $£ 890$. Back in 2014, the GDC's reason for more than doubling the ARF was the anticipated rise in complaint levels that year and in successive years. That never happened so the rise must be reversed.

'Instead of demanding an ARF of $£ 890$ for the fifth year running, the regulator should be compelled to pass the savings on to the registrants who pay the bills; there should be no ifs, ands, or buts about it.'

The BDA says the fee remained the highest charged by any of the UK health regulators and

\section{Fact box on fitness to practise}

- 3,099 in 2014; meaning complaints have fallen collectively by $38 \%$ over the past four years

- How FtP cases were dealt with in 2017: 1,896 triaged; 1,044 assessed, 638 considered by the Investigating Committee or case examiners; 224 referrals to Practice Committee

- Costs of FtP cases - FtP and hearings costs decreased by f5.8 million from 2016 to f20.3 million in 2017

- Speed of the FtP process - 97\% of FtP cases were triaged within ten net working days of receipt in 2017. $65 \%$ of investigation stage cases were completed within the six-month target in 2017 while $50 \%$ of cases received an initial hearing within nine months of referral from the Investigating Committee. The appeals process can take up to 12 months.

continues to be used to top up reserves beyond even the regulator's own stated requirements.

'The GDC needs to set out when it will lower these fees', adds Lockyer. 'We need a regulator prepared to live within its means.'

The Faculty of General Dental Practice

UK also has concerns as its Dean Ian Mills says: 'It is absolutely crucial that the GDC has begun to invest in modernising its organisation, and in particular the Fitness to Practise procedures.

'It is encouraging to see that this is slowly having a positive outcome, although there is still some way to go.

'The GDC has a primary responsibility to protect patients, but this can only be achieved by ensuring that dental teams work in an environment which supports delivery of high quality care. Additional regulatory burdens, whether financial or administrative, make this increasingly challenging. It is important that the GDC recognises this and ensures that its approach to regulation is fair, equitable and proportionate.'

\section{A complex picture}

Despite the criticisms, the GDC believes it is taking the right approach and a spokesperson says: "Whilst there are some strong "good news" stories in relation to reduced costs in our FtP activity due to the investment made in our endto-end review and improvement programme, this does not tell a complete and accurate story in relation to the $£ 5.8$ million. The following

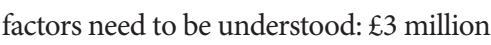
reduction in cost is due to a fall in PCC hearing referrals from 333 in 2016 to 224 in 2017.

'Part of this is due to a decline in incoming cases, but, importantly, part of this was caused by a delay at the casework stage which caused delays in cases reaching PCC. Therefore, this is not a "saving" but rather is better described as "deferred spend" which will be seen in 2018.'

It was also more appropriate to describe the 1,910 'complaints' received in 2017 as 'incoming cases' instead of 'complaints received' because some of the 1,910 complaints were actually received in 2016 but triaged in 2017.

'The GDC's primary purpose is to protect patient safety and maintain public confidence in dental services', says the GDC spokesperson. 'Therefore, in relation to FtP our aim is not to reduce the number of cases, but rather it is to ensure that the GDC is only dealing with those which are appropriate.

'A further stated aim in our Shifting the balance consultation was to improve first-tier complaints, or local resolution. This is a major push for the GDC in our work with partners and the sector as a whole. Work is underway to strengthen this.'

\section{Ripe for complaints}

Particular characteristics of dentists appear to determine how likely they are to have allegations made against them.

A GDC-commissioned report ${ }^{3}$ produced last year by Plymouth University Peninsula Schools of Medicine and Dentistry analysed FtP patterns and found that after controlling for other factors, various groups which were all more likely to have been involved in an FtP case closed at any stage included:

- Males (more than females)

- Both dentists and DCPs in the first ten years of registration

- Registrants with ethnicities recorded as Asian or Other rather than white with the exception of Asian registrants who were less likely than white registrants to have been involved in FtP cases closed at triage (the initial stage of the FtP process) but more likely to have been involved in cases closed at later stages

- Those that hold a primary dental qualification from outside the UK

- The longer registrants had been on the register, the more likely they were to have been involved in an FtP case closed at any stage, with the important exception 
4 of cases closed at Practice Committee (the most serious stage of the FtP process) where those with more time on the register were less likely to have been involved.

The issue of race matches findings of other healthcare regulators such as the General Medical Council (GMC), which has spoken of a persistent 'overrepresentation' of complaints against ethnic minority doctors in recent years though it is unclear if that is to do with their ethnicity or professional performance.

The latest GMC report ${ }^{4}$ looking at the state of medical education and practice found that black and minority ethnic GPs were $20 \%$ more likely to face a patient complaint over fitness to practise and $30 \%$ more likely to be investigated by the GMC.

The GDC has issued figures following a Freedom of Information (FoI) request to show the number of dentists from each country of qualification whose titness to practise was found to be 'impaired' (meaning either suspension, conditions, erasure or a reprimand) between 2013 and 2016.

Looking at all countries combined for 2016, there were 204 dentists whose fitness to practise was 'impaired' and of those, $40.7 \%$ had a non-UK qualification despite that fact that only $28 \%$ of the dental workforce has a qualification from outside the UK.

Heated debate over fitness to practise and regulation looks set to continue.

1. GDC. Annual Report and Accounts: 2017. (20 June 2018). Available at https://www.gdc-uk.org/about/what-we-do/ publications (accessed 10 September 2018).

2. General Dental Council. Shifting the balance: a better, fairer system of dental regulation (January 2018). Available at www.gdc-uk.org/shiftingthebalance (accessed 10 September 2018).

3. Zahra D, Roberts M, Bryce M, O’Brien T, Archer J. Analysis of fitness to practise case data for the General Dental Council (February 2017). Available at https:// www.gdc-uk.org/about/what-we-do/research (accessed 4 September 2018).

4. General Medical Council. The state of medical education and practice in the UK: 2017. 19 December 2017. Available at https://www.gmc-uk.org/-/media/about/ somep-2017-final-full.pdf?la=en\&hash $=3$ FC4B6C2B7EBD840017B908DBF0328CD840640A1 (accessed 4 September 2018).

\section{Dentists invited to apply to join BDA policy body}

Dentists are being invited to submit nominations to be elected to the BDA's Principal Executive Committee (PEC) the body that has overall responsibility for the control and direction of the policy and affairs of the BDA.

Members can self-nominate but need to have three other members to support their candidacy.

Nominations are being sought for the following seats on the PEC:

- UK-wide (one seat)

- Northern Ireland (one seat)

- England North (one seat)

- England South West (one seat)

- England Yorkshire and Humber (one seat).

There are 15 members on the PEC and each person will have a share of overall responsibilities.

Usually this requires attendance at all meetings of the PEC (around five a year); attendance at own country council meetings (usually three a year); attendance at UK Council meetings (around two a year); sitting on one to two sub committees/issue specific forums; and attendance at general meetings of the BDA.

It is anticipated that the approximate time commitment for a member of the PEC will be 20 days per year, with an annual remuneration of $£ 15,000$.

If successful, a person's position on the PEC will last until December 2021, with the opportunity to stand for a further full three-year term of office at that point.

Because membership of the PEC carries significant organisational and legal responsibilities, there is an induction programme for those elected and ongoing training provided.

Nomination forms must be submitted online by 5 pm on 26 October 2018. A link to the online nomination portal can be found at www.bda.org/elections

For more information, please contact the BDA's Election Manager Stephen Skelton by calling 02075634141 or emailing stephen.skelton@bda.org. 